\title{
Effects of methionine and tryptophan on some quantitative traits of silkworm, Bombyx mori L. (Lepidoptera : Bombycidae)
}

\section{Rezina Laz}

Department of Zoology, University of Rajshahi, Rajshahi- 6205, Bangladesh.

\begin{abstract}
The present experiment was carried out to determine the effects of methionine and tryptophan on some quantitative traits of silkworm, Bombyx mori L. Mulberry leaves were treated with 250,500,750 and $1000 \mathrm{ppm}$ of amino acids and were provided to the worms as food. Compared to the controls amino acids (especially 500 and $750 \mathrm{ppm}$ ) significantly increased the fecundity, fertility, adult emergence, developmental periods and longevity of $B$. mori adults but decreased the mortality.
\end{abstract}

Key words: Amino acids, Bombyx mori, fecundity, mortality, longevity.

\section{Introduction}

Like other organisms, nutrition plays a pivotal role in silkworms by improving their commercial characters of silkworms. Silkworm is monophagous, so it requires constituents for its growth derived from the mulberry leaves and the quality of the leaves influences greatly the biology of the worms. According to Dow (1986), lepidopteran larvae are characterized by intense feeding activity and a rapid growth. The alimentary apparatus of these animals is formed by a vestigial foregut, a short hindgut and a wide long midgut. Santos et al. (1984) observed that the digestive and absorptive functions of the larval midgut epithelium are performed by the coordinated activity of two different cell types: columnar cells and goblet cells. Columnar cells are responsible for synthesis and secretion of digestive enzymes. Giordana et al. (1982) observed that columnar cells are responsible for the nutrients absorption. Silkworm requires certain essential sugars, proteins, amino acids and vitamins for its normal growth, survival and also for the growth of its silk glands (Sengupta et al., 1972). Krishnaswami et al. (1971) showed that silkworms exhibit better growth and development due to nutritionally enriched leaves supplementation. Significant developments in the research on silkworm nutrition started with the formulation of artificial diets with different nutrients i.e., proteins, amino acids, and carbohydrates, hormones, vitamins and minerals. Better production of cocoon crops was investigated by many workers like Bose \& Majumder (1989), Reddy et al. (1994), Saha \& Khan (1997a,b), Faruki (1998), Nirwani et al. (1998), Nakamura (2000), Narasimhamurthy \& Govindappa (1988), Islam \& Khan (1993).
The structural components and all the enzymes regulating biochemical transformation of living cells are proteins and hence amino acids suggest a primary class of nutrients. Amino acids are closely related to the biosynthesis of silk proteins as well as to the growth of silk glands of $B$. mori (Ito, 1972). It has been experimentally determined by Bose et al. (1989) that silkworms require 18 amino acids for their adequate nutrition. Amino acids and their derivatives participate in intracellular functions as diverse as nerve transmission, regulation of cell growth and the biosynthesis of various compounds in silkworm (Rodwell, 1993). The requirements of amino acids in $B$. mori are confirmed by different deletion experiments (Qadar et al., 1994; Eid et al., 1989; Khan \& Saha, 1995 and Saha et al.,1994). Krishnappa (1987) reported that supplementation with amino acids reduces the total larval duration and survival percentage. According to Leonardi et al. (2001) nutrient absorption and its modulation are critical for animal growth. They demonstrated that leucine methyl ester (Leu-Ome) can greatly increase the activity of the transport system responsible for the absorption of most essential amino acids in larval midgut of the silkworm.

Considering the key role played by amino acid absorption in silkworm nutrition and development, attempts have been made here to assess the effects of methionine and tryptophan on the fecundity, fertility, mortality, adult emergence, longevity and developmental periods of the silkworm, B. mori L.

\section{Materials and Methods}

A high-yielding multivoltine breed of the silkworm, BSRI-83/3 was procured from the Silkworm Germplasm Bank of Bangladesh Sericulture 
Research and Training Institute, Rajshahi, and reared in the Animal Genetics and Breeding Laboratory, Department of Zoology, University of Rajshahi. Standard rearing techniques were followed (Krishnaswami, 1979). After hatching, the larvae were reared up to $2^{\text {nd }}$ instar on fresh mulberry leaves (Morus alba).

Water soluble amino acids L-methionine and Ltryptophan were collected from the Department and four different concentrations $(250,500,750$ and $1000 \mathrm{ppm}$ ) were prepared. The fresh mulberry leaves were dipped in different concentrations of of the amino acid solutions separately and dried up by fanning and chopped. Then the leaves were given to the silkworms on their 3rd instar first feeding. Control insects were reared simultaneously on untreated leaves. Three replications per concentration containing 30 healthy larvae were maintained. The treatments were continued up to spinning and succeeded by parental and $F_{1}$ generation. The data were collected and used for statistical analysis.

\section{Results and Discussion}

In case of fecundity, the maximum numbers of eggs laid at $750 \mathrm{ppm}$ were 531.53+25.96 $(605.73+49.72)$ in the parental and $F_{1}$ generation in methionine and 536.33+21.64 (615.87+60.39) in tryptophan supplementation. Analysis of variance showed highly significant differences in eggs between the generations only. The highest fertility was also found at $750 \mathrm{ppm}$ in the parental and $F_{1}$ generation $(96.73+1.60,97.18+1.12$ and $97.25+1.23,97.83+0.91)$ in the methionine and tryptophan supplementation, respectively in fertility. Analysis of variance showed highly significant differences between the concentrations and generations (8.77 and 18.89, $P<0.001$ in methionine and 16.16 and 21.19, $P<0.001$ in tryptophan) (Table 1). The lowest larval and pupal mortalities was obtained at $500 \mathrm{ppm}$ in parental and $F_{1}$ generation (Fig.1). Larval mortality showed significant difference between generations (3.658, $\mathrm{P}<0.05)$ in case of methionine and between concentrations $(3.034, \quad \mathrm{P}<0.05)$ in tryptophan supplementation. But pupal mortality showed insignificant differences $(0.375,0.244,1.026$ and 0.798 respectively). Figure 2 demonstrates that the highest percentage of adult emerged at 500 ppm $(95.56+3.85,90.00+3.33$ in methionine and $96.67+3.34,92.22+1.92$ in tryptophan) in the parental and $F_{1}$ generation. Analysis of variance also showed significant differences (9.114, 10.911, $P<0.001$ and 8.903, $P<0.001,4.834$, $\mathrm{P}<0.05)$, between both concentrations and generations. Developmental periods i.e., larval and pupal period were significantly reduced in the parental and $F_{1}$ generations due to methionine (11.86, 2624.79, 27.23 and 405.30, $\mathrm{P}<0.001$ ) and tryptophan (10.06, 2868.69, 36.49 and 424.67, $\mathrm{P}<0.001)$ supplementation (Table 1). It was observed that methionine and tryptophan enhanced the male and female longevity at 750 ppm when compared with control line. Analysis of variance exhibited highly significant differences between the concentrations $(4.73$ and 4.75, $\mathrm{P}<0.01$ in methionine and 7.08 and 12.17, $\mathrm{P}<0.001$ in tryptophan) and between the generations (4.15, $P<0.01$ and $460.13 \mathrm{~m} P<0.001$ in methionine and 16.38 and $390.15, P<0.001$ in tryptophan respectively) (Table 3 ).

Krishnappa (1987) found that fecundity and fertility were well pronounced due to amino acid supplementation. He also reported that amino acids reduce the total larval duration and mortality of larvae and pupae. Similarly Saha et al. (1994) observed that proline and leucine enhanced the reproductive potentiality (i.e., fecundity, fertility etc.). Kabila et al. (1994) recorded the reduced larval duration in $B$. mori reared on feed supplemented with neutralized ascorbic acid. Khan \& Saha (1995) also observed that alanine and glutamine significantly increased the growth and development and decreased the larval and pupal periods. According to Horie \& Watanabe (1983), if growth depends on a large number of differentiated physiological activities, the functional properties of the intestine and its ability to absorb efficiently, amino acids can influence the development of the whole organism. In $B$. mori, in particular, up to $65 \%$ of digested nitrogen is utilized for silk production during the last instar and the level of dietary protein and limiting amino acids in the diet strongly affects larval growth and silk production. Leonardi et al. (2001) demonstrated that intestinal amino acid absorption is an important step in nitrogen metabolism and directs the biological development of the whole organism. They also showed that leucine-methyl-ester (Leu-Ome) can greatly increase the activity of the transport system responsible for absorption of most essential amino acids in the larval midgut of B. mori. They recorded the leucine uptake activation by Leu-Ome in brush border membrane vesicles and in the apical membrane of epithelial cells in the midgut incubated in vitro and observed that the addition of this strong activator of amino acid absorption to diet significantly affected the larval development. 
Table 1. Developmental periods of $B$. mori feed on amino acid-treated mulberry leaves

\begin{tabular}{|c|c|c|c|c|c|c|}
\hline \multirow{2}{*}{ Amino acids } & \multirow{2}{*}{$\begin{array}{l}\text { Concentrations } \\
\text { (ppm) }\end{array}$} & \multicolumn{2}{|c|}{ Larval period (Mean \pm SD) } & \multicolumn{2}{|c|}{ Pupal period (Mean \pm SD) } & \multirow{2}{*}{ F-values } \\
\hline & & Parental & $\mathrm{F}_{1}$ & Parental & $\mathrm{F}_{1}$ & \\
\hline \multirow{5}{*}{ Methionine } & 0 (Control) & $19.61 \pm 0.69$ & $17.64 \pm 0.64$ & $9.78 \pm 0.42$ & $9.18 \pm 0.42$ & \multirow{5}{*}{$\begin{array}{l}{ }^{\mathrm{Aa}} 11.86^{\star \star \star} \\
{ }^{\mathrm{Ab}} 2624.79^{\star \star \star} \\
\mathrm{Ba}_{2} 27.23^{\star \star \star} \\
{ }^{\mathrm{Bb}} 405.30^{\star \star \star}\end{array}$} \\
\hline & 250 & $19.51 \pm 0.63$ & $17.39 \pm 0.49$ & $9.41 \pm 0.49$ & $8.68 \pm 0.67$ & \\
\hline & 500 & $19.39 \pm 0.54$ & $17.31 \pm 0.47$ & $9.43 \pm 0.49$ & $8.51 \pm 0.71$ & \\
\hline & 750 & $19.45 \pm 0.63$ & $17.39 \pm 0.49$ & $9.38 \pm 0.49$ & $8.33 \pm 0.55$ & \\
\hline & 1000 & $19.84 \pm 0.73$ & $17.62 \pm 0.49$ & $9.35 \pm 0.48$ & $8.57 \pm 0.79$ & \\
\hline \multirow{5}{*}{ Tryptophan } & 0 (Control) & $19.61 \pm 0.69$ & $17.64 \pm 0.64$ & $9.77 \pm 0.42$ & $9.18 \pm 0.42$ & \multirow{5}{*}{$\begin{array}{l}{ }^{\mathrm{Aa}} 10.06^{\star \star \star} \\
{ }^{\mathrm{Ab}} 2868.69^{\star \star \star} \\
\mathrm{Ba}_{36.49^{\star \star \star}} \\
{ }^{\mathrm{Bb}} 424.67^{\star \star \star}\end{array}$} \\
\hline & 250 & $19.49 \pm 0.59$ & $17.36 \pm 0.48$ & $9.61 \pm 0.50$ & $8.56 \pm 0.70$ & \\
\hline & 500 & $19.38 \pm 0.53$ & $17.31 \pm 0.46$ & $9.39 \pm 0.49$ & $8.36 \pm 0.55$ & \\
\hline & 750 & $19.40 \pm 0.54$ & $17.34 \pm 0.48$ & $9.30 \pm 0.46$ & $8.19 \pm 0.39$ & \\
\hline & 1000 & $19.71 \pm 0.65$ & $17.53 \pm 0.40$ & $9.23 \pm 0.50$ & $8.82 \pm 0.92$ & \\
\hline
\end{tabular}

Note: $\mathrm{A}=$ Larval period, $\mathrm{B}=$ Pupal period; $\mathrm{a}=$ between concentrations, $\mathrm{b}=$ between generations; ${ }^{\star \star \star} \mathrm{P}<0.001$

Table 2. Effects of amino acids on the reproduction of $B$. mori females

\begin{tabular}{|c|c|c|c|c|c|c|}
\hline \multirow{2}{*}{ Amino acids } & \multirow{2}{*}{$\begin{array}{l}\text { Concentrations } \\
(\mathrm{ppm})\end{array}$} & \multicolumn{2}{|c|}{ Fecundity (Mean \pm SD) } & \multicolumn{2}{|c|}{ Fertility (\%) (Mean \pm SD) } & \multirow{2}{*}{ F-values } \\
\hline & & Parental & $\mathrm{F}_{1}$ & Parental & $F_{1}$ & \\
\hline \multirow{5}{*}{ Methionine } & 0 (Control) & $509.13 \pm 42.37$ & $569.53 \pm 40.94$ & $93.72 \pm 1.21$ & $95.46 \pm 2.30$ & \multirow{5}{*}{ 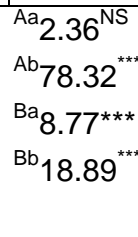 } \\
\hline & 250 & $517.07 \pm 48.03$ & $579.13 \pm 38.16$ & $95.43 \pm 1.86$ & $96.45 \pm 1.58$ & \\
\hline & 500 & $528.93 \pm 39.36$ & $590.93 \pm 54.24$ & $96.02 \pm 1.48$ & $97.11 \pm 1.34$ & \\
\hline & 750 & $531.53 \pm 25.96$ & $605.73 \pm 49.72$ & $96.73 \pm 1.60$ & $97.18 \pm 1.12$ & \\
\hline & 1000 & $513.87 \pm 34.03$ & $571.47 \pm 59.88$ & $94.84 \pm 2.21$ & $96.52 \pm 1.76$ & \\
\hline \multirow{5}{*}{ Tryptophan } & 0 (Control) & $509.13 \pm 42.37$ & $569.53 \pm 40.94$ & $93.72 \pm 1.21$ & $95.46 \pm 2.30$ & \multirow{5}{*}{ 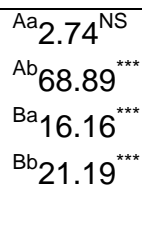 } \\
\hline & 250 & $523.13 \pm 45.26$ & $586.33 \pm 55.59$ & $95.09 \pm 1.57$ & $96.63 \pm 1.45$ & \\
\hline & 500 & $532.47 \pm 34.58$ & $598.33 \pm 51.92$ & $96.75 \pm 1.86$ & $97.45 \pm 1.62$ & \\
\hline & 750 & $536.33 \pm 21.64$ & $615.87 \pm 60.39$ & $97.25 \pm 1.23$ & $97.83 \pm 0.91$ & \\
\hline & 1000 & $516.87 \pm 28.08$ & $576.47 \pm 79.63$ & $95.28 \pm 1.96$ & $96.67 \pm 1.20$ & \\
\hline
\end{tabular}

Note: $A=$ fecundity, $B=$ fertility; $a$ = between concentrations, $b=$ between generations

$\star \star \star P<0.001, N S=$ non-significant

Table 3. Longevity of $B$. mori adults resulting from larvae feed on amino acid-treated mulberry leaves

\begin{tabular}{|c|c|c|c|c|c|c|}
\hline \multirow{2}{*}{ Amino acids } & \multirow{2}{*}{$\begin{array}{l}\text { Concentrations } \\
(\mathrm{ppm})\end{array}$} & \multicolumn{2}{|c|}{ Longevity of males (Mean \pm SD) } & \multicolumn{2}{|c|}{ Longevity of females (Mean \pm SD) } & \multirow{2}{*}{ F-values } \\
\hline & & Parental & $\mathrm{F}_{1}$ & Parental & $\mathrm{F}_{1}$ & \\
\hline \multirow{5}{*}{ Methionine } & 0 (Control) & $3.40 \pm 0.74$ & $3.73 \pm 0.70$ & $6.47 \pm 0.52$ & $8.33 \pm 0.49$ & \multirow{5}{*}{$\begin{array}{l}{ }^{\mathrm{Aa}} 4.73^{\star \star} \\
{ }^{\mathrm{Ab}} 4.15^{\star \star} \\
{ }^{\mathrm{Ba}} 4.75^{\star \star} \\
{ }^{\mathrm{Bb}} 460.13^{\star \star \star}\end{array}$} \\
\hline & 250 & $3.60 \pm 0.51$ & $3.87 \pm 0.83$ & $6.60 \pm 0.63$ & $8.60 \pm 0.83$ & \\
\hline & 500 & $3.80 \pm 0.68$ & $3.93 \pm 0.80$ & $6.73 \pm 0.46$ & $8.80 \pm 0.77$ & \\
\hline & 750 & $3.93 \pm 0.70$ & $3.93 \pm 0.46$ & $6.87 \pm 0.35$ & $8.93 \pm 0.83$ & \\
\hline & 1000 & $3.13 \pm 0.46$ & $3.47 \pm 0.52$ & $6.33 \pm 0.49$ & $8.40 \pm 0.51$ & \\
\hline \multirow{5}{*}{ Tryptophan } & 0 (Control) & $3.40 \pm 0.74$ & $3.73 \pm 0.73$ & $6.47 \pm 0.52$ & $8.33 \pm 0.49$ & \multirow{5}{*}{$\begin{array}{l}{ }^{\mathrm{Aa}} 7.08^{\star \star \star} \\
{ }^{\mathrm{Ab}} 16.38^{\star \star \star} \\
{ }^{\mathrm{Ba}} 12.17^{\star \star \star} \\
{ }^{\mathrm{Bb}} 390.15^{\star \star \star}\end{array}$} \\
\hline & 250 & $3.53 \pm 0.52$ & $4.00 \pm 0.65$ & $6.93 \pm 0.46$ & $8.93 \pm 0.70$ & \\
\hline & 500 & $3.67 \pm 0.49$ & $4.20 \pm 0.56$ & $7.07 \pm 0.68$ & $9.07 \pm 0.59$ & \\
\hline & 750 & $4.07 \pm 0.70$ & $4.33 \pm 0.49$ & $7.20 \pm 0.70$ & $9.27 \pm 0.70$ & \\
\hline & 1000 & $3.33 \pm 0.48$ & $3.67 \pm 0.49$ & $6.53 \pm 0.52$ & $8.27 \pm 0.59$ & \\
\hline
\end{tabular}

Note: $\mathrm{A}=$ Longevity of males, $\mathrm{B}=$ Longevity of females; $\mathrm{a}=$ between concentrations, $\mathrm{b}=$ between generations

${ }^{\star *} \mathrm{P}<0.01,{ }^{\star \star *} \mathrm{P}<0.001$ 

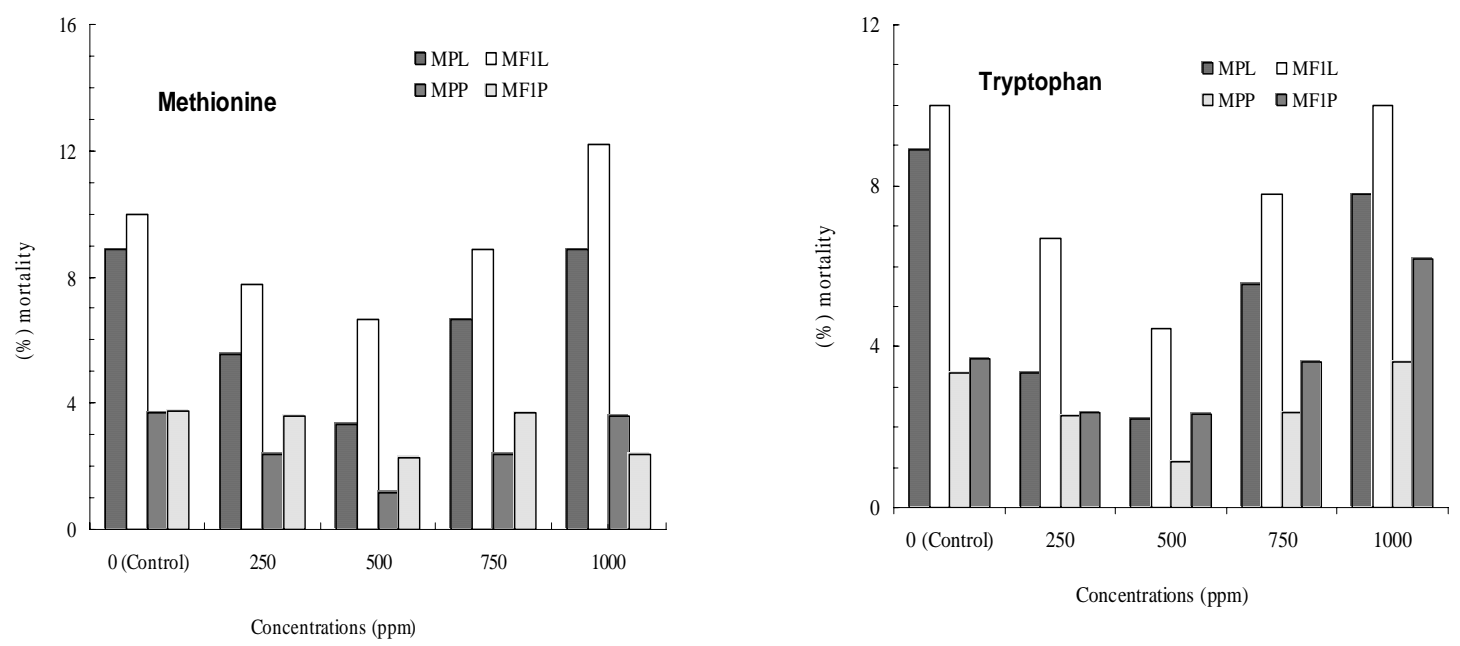

Fig. 1: Mortalities in larval and pupal stages in $B$. mori resulted from amino acid-treated leaves. $\mathrm{MPL}=$ mortality of parental larvae, $\mathrm{MF}_{1} \mathrm{~L}=$ mortality of $\mathrm{F}_{1}$ larvae $\mathrm{MPP}=$ mortality of parental pupae, $\mathrm{MF}_{1} \mathrm{P}=$ mortality of $\mathrm{F}_{1}$ pupae
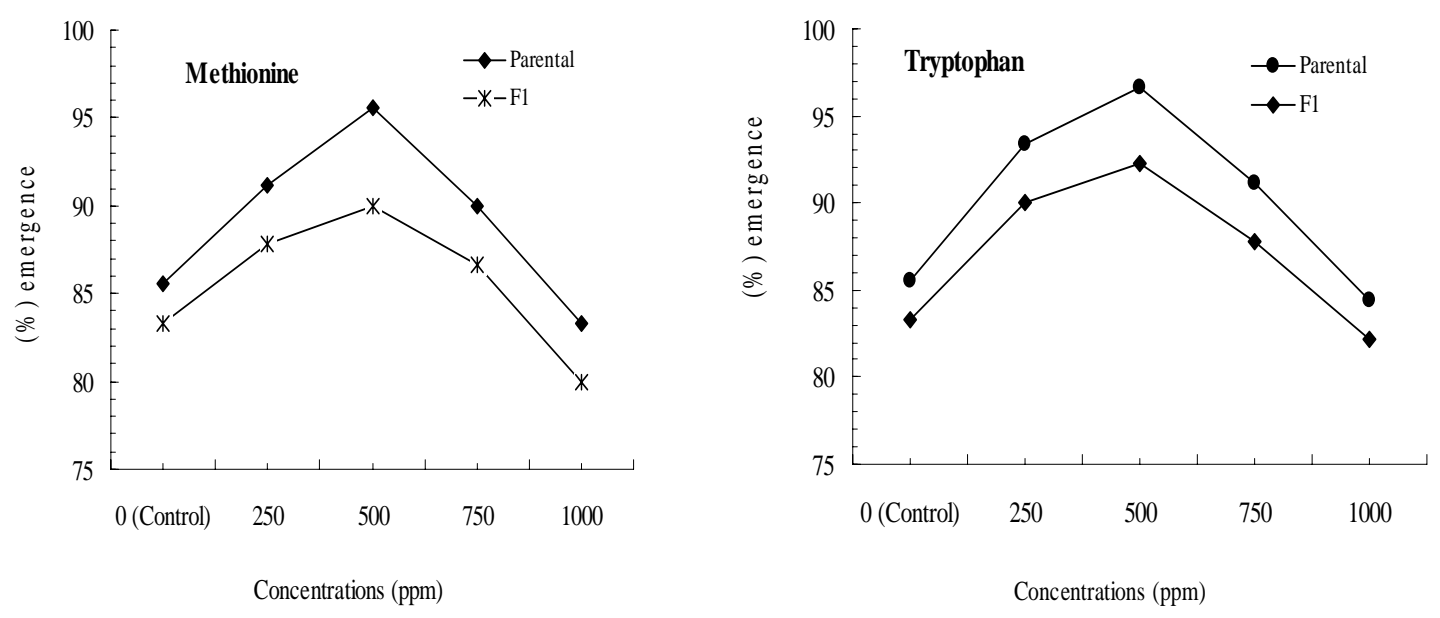

Fig. 2: Adult emergence (\%) in B. mori from amino acid-treated leaves.

\section{Acknowledgements}

The author would like to thank the Chairman, Department of Zoology, Rajshahi University, Rajshahi for providing necessary facilities and the Director, Bangladesh Sericulture Research and Training Institute, Rajshahi for supplying the experimental silkworm eggs. She also gratefully thanks to Professor Dr. Selina Parween, Professor Dr. Saiful Islam Faruki and Professor Dr. A.M. Saleh Reza for their helpful suggestions.

\section{References}

Bose, P.C. \& Majumder, S.K.1989. Amino acid requirements in silkworm, Bombyx mori L. Indian silk. 28 (4): 41-43.
Bose, P.C., Majumder, S.K. \& Sengupta, K.1989. Role of amino acids in silkworm nutrition and their occurrence in haemolymph, silk glands and silk cocoons- A review. Indian J. Seric. 28(1): 17-31.

Dow, J.A.T. 1986. Insect midgut function. Adv. Insect Physiol. 19: 187-328.

Eid, M.A.A., El-Nakkady, A.N. \& Salch, M.A. 1989. Effect of supplementary amino acids on silk secretion by larvae of Philosomia ricini (Boisd). Indian J. Seric. 28(2): 224- 232.

Faruki, S.I. 1998. Nutritive effect of Thianomin ${ }^{(R)}$ enriched mulberry leaves on the silkworm Bombyx mori L. Univ. j. zool. Rajshahi Univ. 17: 39-44.

Giordana, B., Sacchi, V.F., \& Hanozet, G.M. 1982. Intestinal amino acid absorption in lepidopteran larvae. Biochem. Bhiophys. Acta. 692: 81-88. 
Horie, Y. \& Watanabe, K. 1983. Effect of various kinds of dietary protein and supplementation with limiting amino acids on growth, haemolymph components and uric acid excretion in the silkworm, Bombyx mor. J. Insect Physiol. 29: 187-199.

Islam, M.Z. \& Khan, A.R. 1993. Growth and development of the mulberry silkworm, Bombyx mori L. (Lepidoptera: Bombycidae) on feed supplemented with manganese sulphate. J. bio-sci. 1: $21-30$.

Ito, T. 1972. Amino acid nutrition of the silkworm, Bombyx mori. Proc. Jap. Acad. 48: 613-617.

Kabila, V., Subburathinam, K.M. \& Chitty, J.S. 1994. Growth and economic characters of silkworm, Bombyx mori L. on feed enriched with neutralized aspartic acid. Indian J. Seric. 33 (1): 80-81.

Khan, A.R. \& Saha, B.N. 1995. Growth and development of the mulberry silkworm, Bombyx mori L. on feed supplemented with alanine and glutamine. Sericologia. 35(4): 657-663.

Krishnappa, J.B. 1987. Influence of amino acids supplementation on growth and development of mulberry silkworm, Bombyx mori L. P. G. Degree Thesis, Univ. of Agricultural Science. Bangalore, India.

Krishnaswami, S., Kumararaj, S.S., Vijayarachavan , K. \& Kastviswanathan, K. 1971. Silkworm feeding trials for evaluating the quality of mulberry as in influenced by variety, spacing and nitrogen fertilization. Indian J. Seric, 10(I): 79-70.

Krishnaswami, S. 1979. Improved method of rearing young age (chawki) silkworms. Central Silk Board. Bombay. India. 24 pp.

Leonardi, M.G., Fianda , L., Casartelli, M., Cappellozza, S. \& Giordana, B. 2001. Modulation of leucine absorption in the larval midgut of Bombyx mori (Lepidoptera: Bombycidae). Comp. Biochem. and Physiol. Part A 129 : 665-672.

Nakamura, M. 2000. Homeostasis and physiology of vitamin $\mathrm{B}_{2}$ of the silkworm, Bombyx mori. Dept of Sericulture, National Inst. of Sericulture and Entomological Sci. 1-2. Ohwashi, Tsukuba, Japan.
Narasimhamurthy, C.V. \& Govindappa,S. 1988. Effect of cobalt on silkworm growth and cocoon crop performance. Indian J. Seri. 27(I): 45-47

Nirwani, R.B., Hugar, I.I. \& Kaliwal, B.B. 1998. Supplementation of riboflavin on economic parameters and biometrical Changes of the silkworm, B. mori L. Bull. Sericult. Res. 9: 37-41.

Qader, M. A., Haque, R. \& Abser, N. 1994. Amino acid contents in posterior silk gland of Bombyx mori (Lepidoptera: Bombycidae) influenced the quality of mulberry leaves. Bull. Sericult. Res. 5: 63-68.

Reddy, V.R., Magadum, K.S.B., Meera, V. \& Datta, R.K. 1994. Metabolic significant of vertebrate type steroids in silkworm, Bombxy mori, L. Indian J. Seric. 33 (I): 6-11.

Rodwell, V.W. 1993. Amino acids (Harper's Biochemistry. $23^{\text {rd }}$ edition, R.K.Murray, D.K.Granner, P.A. Mayes and V.W. Rodwell eds.), Appleton \& Lange, Connecticut, USA. 23-32 pp.

Saha, A.K. Rahman, M.S., Saha, B.N. \& Uddin, M. 1994. Effect of proline and leucine on the growth and development of silkworm Bombyx mori L. Univ. j. zool. Rajshahi Univ. 13: 75-79.

Saha,B.N. \& Khan, A.R. 1997a. The nutritive effects of Sinafort ${ }^{(R)}$ on Bombyx mori L. Entomon. 22(I): 29-34.

Saha, B.N. \& Khan, A.R. 1997b. Effects of vertebrate sex- hormone on Bombyx mori L. Sericologia 37(I): 19-25.

Santos, C.D., Ribeiro, A.F., Ferreira, C. \& Terra, W.R. 1984. The larval midgut of the casava hornworm (Erinnys ello). Ultrastructure, fluid fluxes and secretory activity in relation to the organization of digestion. Cell Tissue Res. 237: 565-574.

Sengupta, K., Singh, B.D. \& Mustafi, C. 1972. Nutrition of silkworm, Bombyx mori L. I. Studies on the enrichment of mulberry leaf with various sugars, proteins, amino acids and vitamins for vigorous growth of the worm and increased cocoon crop production Indian J. Sci. 11 (I): 11-27. 